\title{
COMPLICATIONS OF EXTERNAL CONDOM DRAINAGE
}

\author{
By Hossein Golji, M.D.
}

Spinal Cord Injury Service, Veterans Administration Medical Center, Long Beach, Califorina and the Department of Surgery, Division of Urology, University of California, Irvine, California

Key words: Condom sheath; Urinary drainage; Spinal paralysis.

\section{Introduction}

THE most commonly accepted method of urinary drainage in acute spinal cord injured patients is intermittent catheterisation as part of rehabilitation of the bladder. Except for a group of SCI patients who, under unusual circumstances,
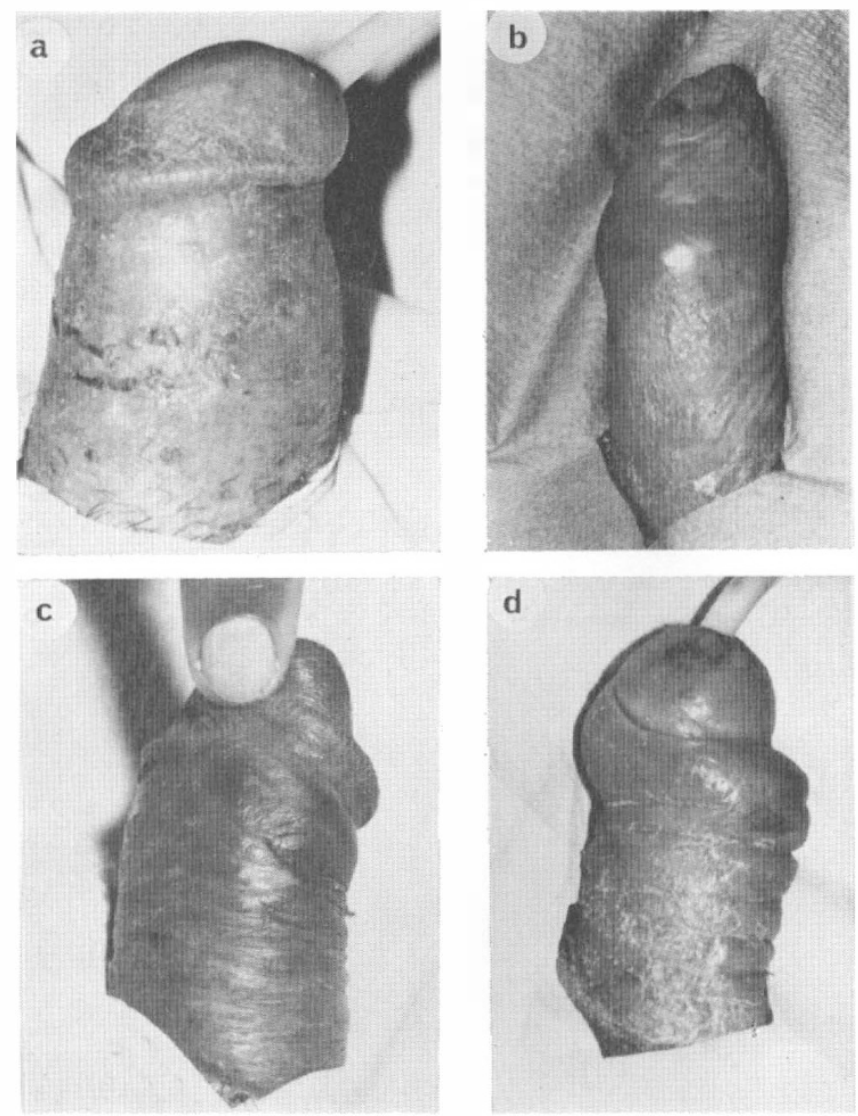

FIG. I

a, Irritative or allergic reactions. b, Effect of urine on the skin. c \& d, Severe allergic reaction. 
remain on catheter drainage, the majority of them are rehabilitated and become catheter free to use external condom drainage for collection of urine.

It is true that condom drainage is the proper means to keep the male patient with reflex bladder and/or incontinence dry, but, is it also true that application of condoms is as harmless as it appears to be?

As the result of evaluating and caring for numerous SCI patients wearing condom drainage, we have come to understand that serious complications may result from the improper application of condoms. Some of these complications are referred to by other authors while discussing the values of Urihesive (Leval \& Louis, I978-79), efficiency of condom urinals versus the rubber duct with penile sheath (Lawson \& Cook, I978-79), and problems associated with external urinary collectors (Naningg \& Rosen, 1975). However, most of the complications referred to by these authors are the ones that were due to the use of rubber ducts with a penile sheath.

\section{Material and Methods}

For the purpose of this study, our present inpatients and our file of interesting cases during the last 3 years were reviewed and evaluated. In the reviewed patients with condom complications their ages ranged between 20 and 70 . About 50 per cent of them were quadriplegics and the rest of them paraplegics. The level of their spinal cord damage was variable and more than 60 per cent of them had non-service-connected injuries such as anto accident, sports, gunshot wound, etc.

All the patients selected for this presentation, except for three, were admitted to hospital for reasons other than that of complaining of problems concerned with their condom drainage. However, the abnormalities related to condom application were mostly discovered during physical examination, daily care, changing the condom or after cysto-urethroscopy. All these patients had routine laboratory and X-ray evaluation and some of them underwent specific studies such as urodynamics, for other reasons.
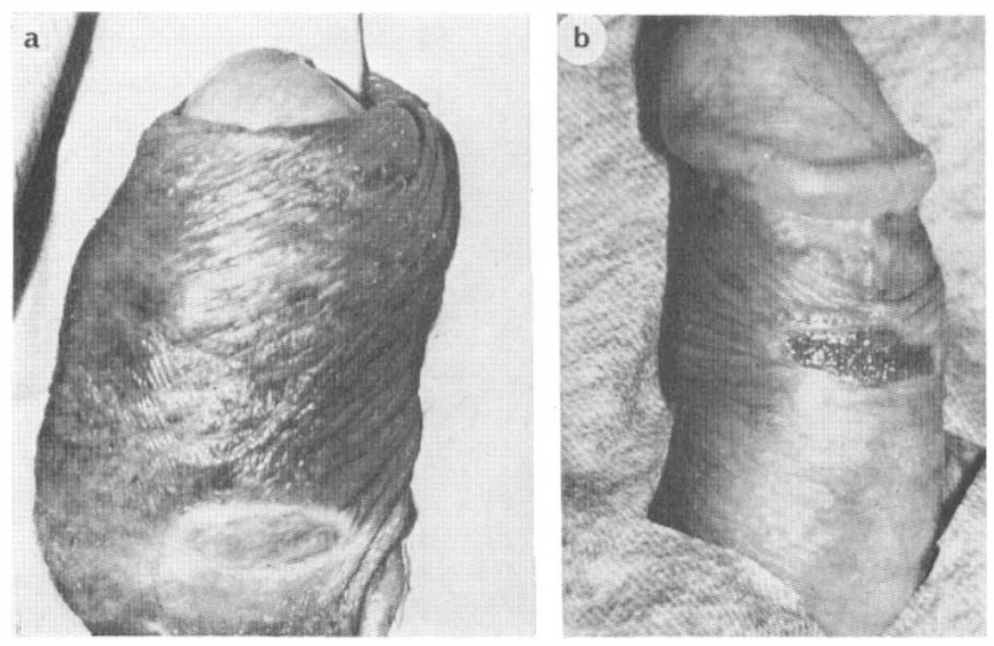

FIG. 2

Pressure sores. A \& B, Effect of roller ring of the condom. 
Abnormal findings

The complications related to the application of a condom for urinary drainage, in SCI patients, may be classified as irritative, allergic or compressive in aetiology. The former two usually involve the skin, and the latter the skin, the corpora and/or the urethra.

Irritative or Allergic Reactions-These are the most common complication.
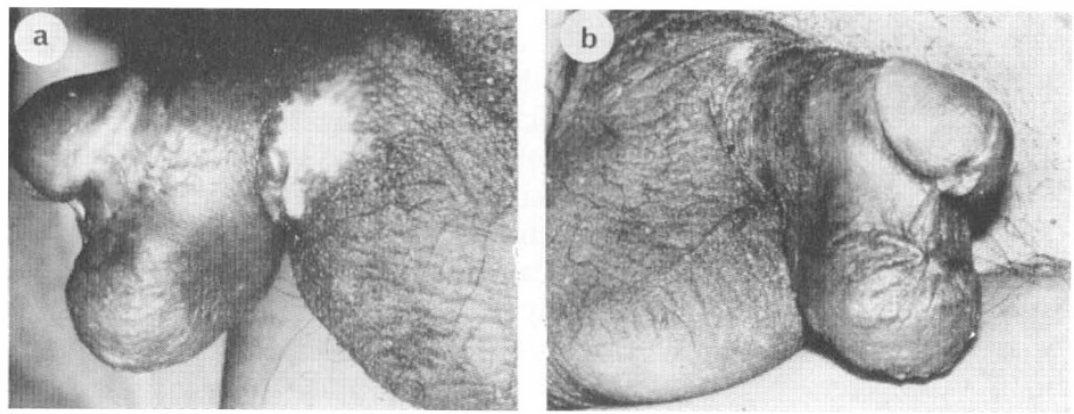

FIG. 3

A \& B, Pressure sore and severe oedema of skin resembling a scrotal sac.
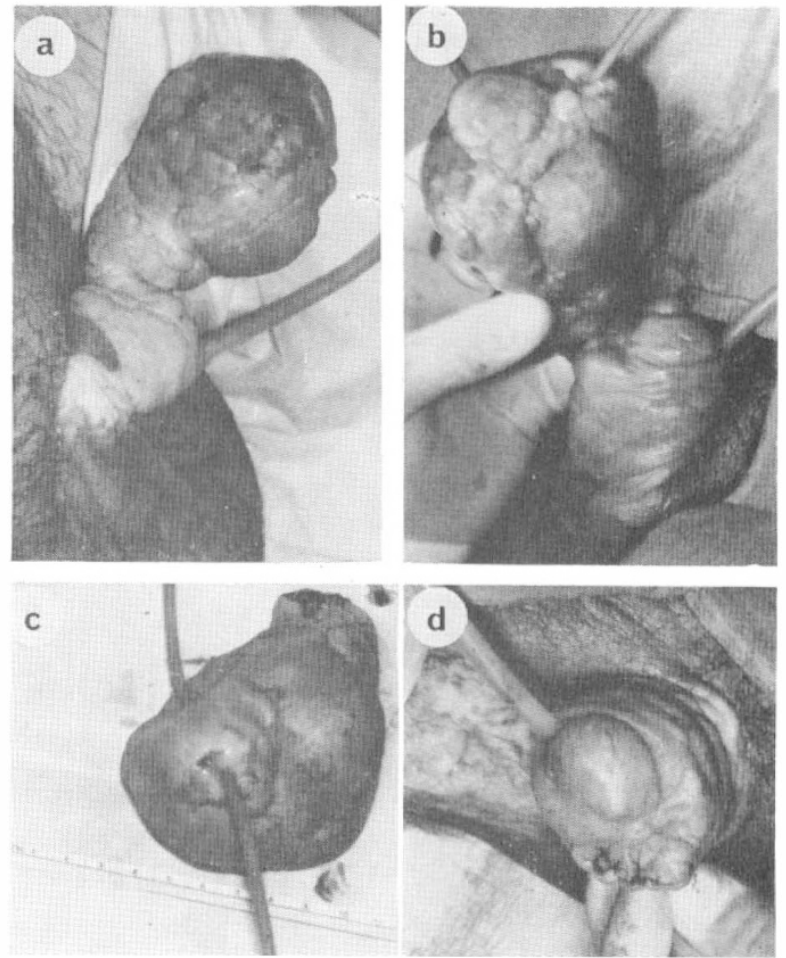

FIG. 4

Advanced oedema and fibrolipomatosis of skin resulting from pressure of tape. A \& B, Before surgery. C \& D, Removed tumour mass. 
The allergic reactions may be due to latex or plastic materials used in the structure of condom, the cements, adhesive substances and other kind of glues utilised for placement of the condom on the penis. The extent of skin reactions may be very limited, such as minimal skin rash and erythema, or very extensive, causing maceration of the epidermis (Fig. I). In some instances the irritation is the result of poor urinary drainage, causing repeated distention of the condom and soaking the skin of the penis in urine (Fig. I, B).

Compressive Effects-The compressive complications of condom application stem from either the proximal hard roller ring of the condom and/or the different kind of tapes used to secure the condom in place. Either of these compressive elements may cause penetrating or non-penetrating lesions.

Penetrating Lesions-Due to the lack of pressure and/or pain sensation in most of the SCI patients, the hard ring of the condom causes a gradual pressure defect, ischaemia, and necrosis of the skin without patients realising it. If the condition is not detected early enough the ring may cut into the skin and subcutaneous tissues (Fig. 2). Also, application of tapes on the penis alone or in conjunction with the condom rings may again cause pressure defects ranging from a localised skin lesion to involvement of the corpora, incomplete amputation of penis and/or gangrene of the penis necessitating amputation (Figs 3, 4, 5 and 6).
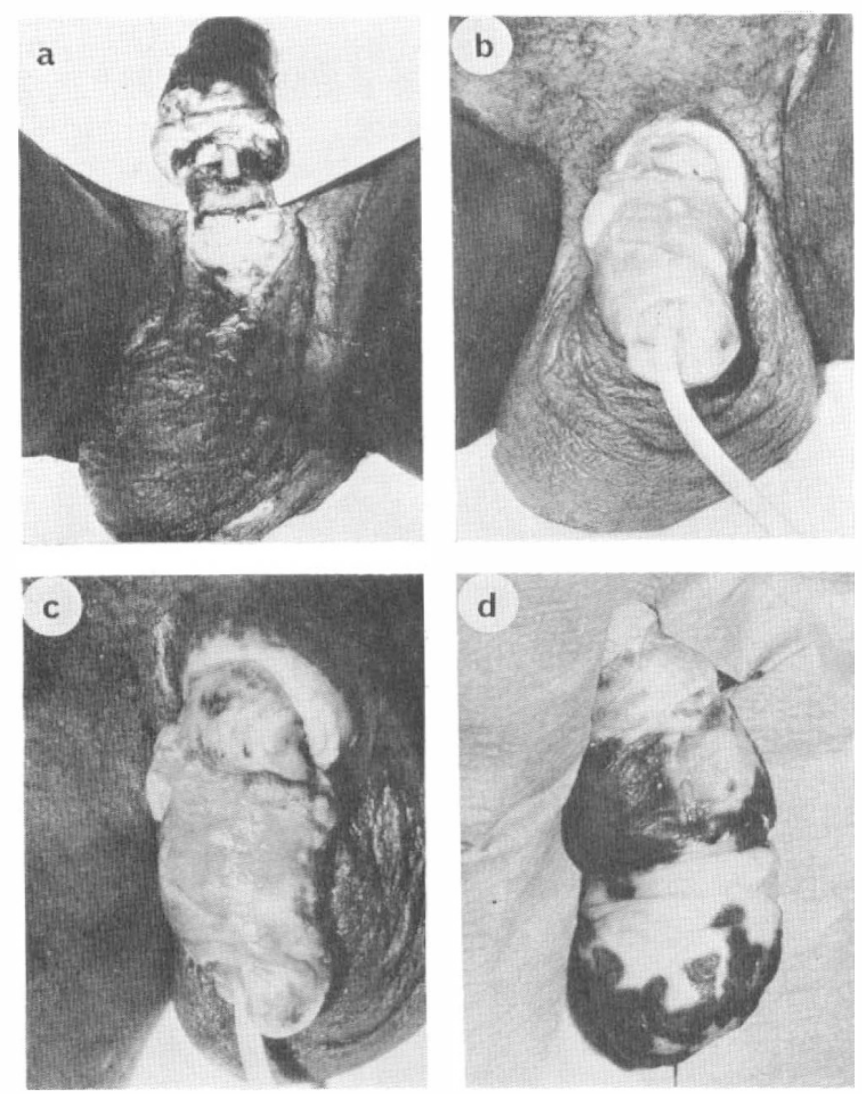

FIG. 5

Partial circular amputation of penis resulting from tape. A, On admission. B, C \& D, Results of several operations. 

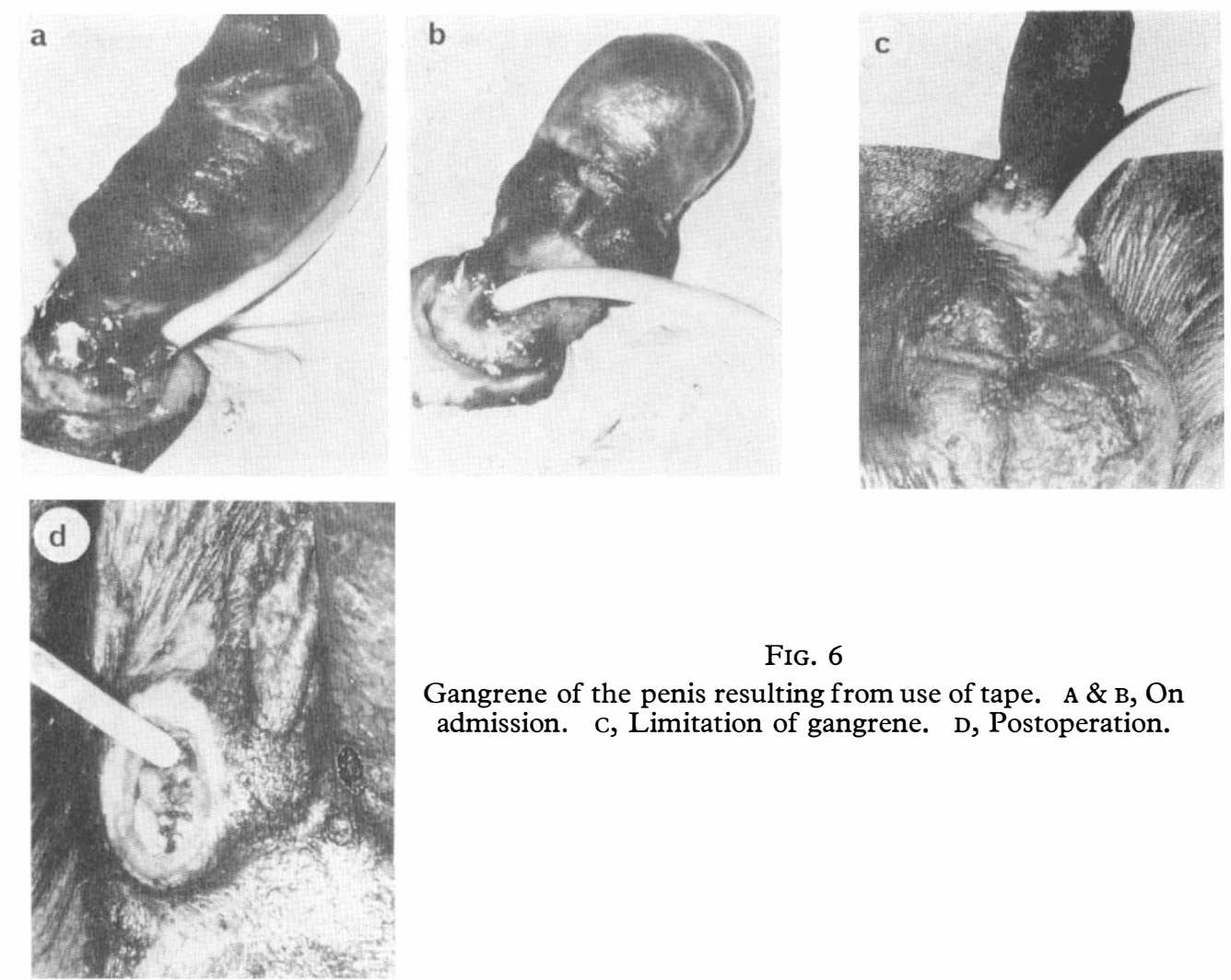

FIG. 6

Gangrene of the penis resulting from use of tape. A \& B, On admission. C, Limitation of gangrene. D, Postoperation.

Non-penetrating Lesions-The compression of the penis by the hard roller ring of the condom, or by the tapes, may only cause oedema of the prepuce (Fig. 3) and/or affect the urethral calibre without any visible penile lesion. The partial constriction of the urethra slows down the flow of urine, increases the intraurethral pressure proximal to constricted area, and consequently encourages the formation of urethral dilatation or urethral diverticulum.

The changes in urethral calibre take place gradually, and in most instances ventrally. If the cause of the deformity is not corrected, the dilatation of urethra or urethral diverticulum will continue to grow (Fig. 7). From this stage on the changes may become so impressive that the urethral diverticulum becomes as large as the bladder itself and/or the dilated urethra competes with the size of a loop of large intestine Fig. 8). Of course, increase in the intraurethral pressure, stagnation of urine and dilation of urethra gradually extends proximally to the rest of urinary tract (Fig. 8, D) and aggravates the already present complications.

\section{Signs and symptoms}

In most of the SCI patients, the sensory feelings are absent and they remain asymptomatic, in spite of the fact that they may have serious penile or urethral lesions. However, they may bring their problems to the attention of staff as a result of visual awareness, urinary or general sepsis and sometimes with the signs and symptoms of gangrene of the penis (Figs 3, 4, 5 and 6). 

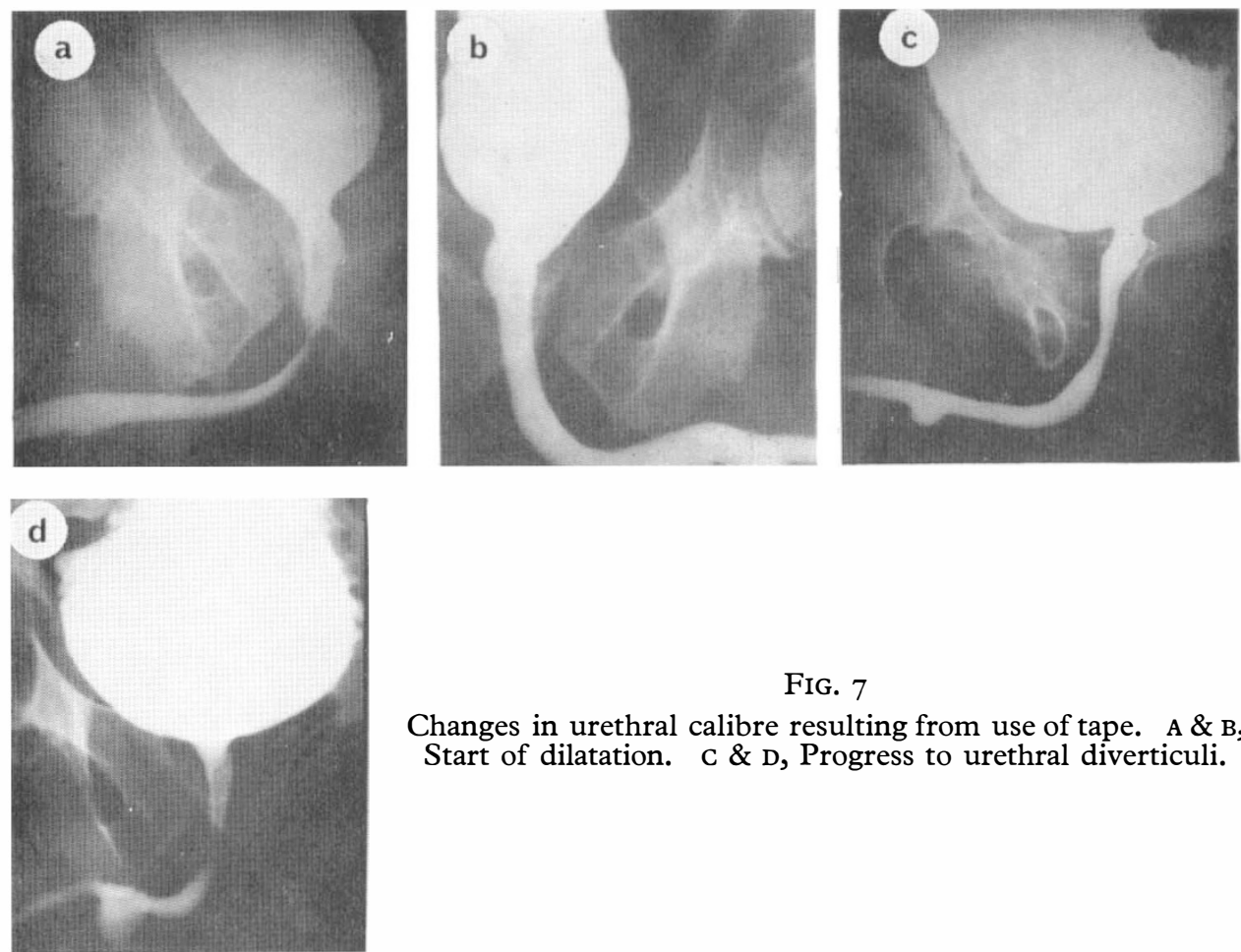

FIG. 7

Changes in urethral calibre resulting from use of tape. A \& B, Start of dilatation. C \& D, Progress to urethral diverticuli.

\section{Diagnosis and Treatment}

Diagnosis and treatment of allergic reactions would be the same as in nonSCI patients. However, the temporary discontinuance of condom drainage in favour of intermittent catheterisation or urethral indwelling catheter might become necessary. The treatment of compressive complications of condom drainage is dependent on the extent of tissue damage. This may vary from temporary discontinuance of condom drainage (Fig. 2) to complicated surgical procedures and amputation of penis (Figs 3, 4, 5 and 6).

\section{Prohylactic treatments}

These are the most important preventive measures and the easiest steps to take. Besides the importance of daily observation of patient's genitalia and local hygiene, the effectiveness of preventive measures is based on only three words, 'DO NOT CONSTRICT'. To comply with this motto, the size of the condom, the roller ring of the condom and the adhesive tapes generally used to wrap around the penis, should seriously be considered. The size of condom should be proportionate to the size of penis to prevent difficulty in application of it and to eliminate compression of penis.

The roller ring of the condom is a danger to the penis and it should be removed after the condom is applied, even if it is not too tight for the size of the penis. The mere pressure of the hard ring at the peno-scrotal junction causes pressure defect. We have requested our suppliers of condoms to modify their 

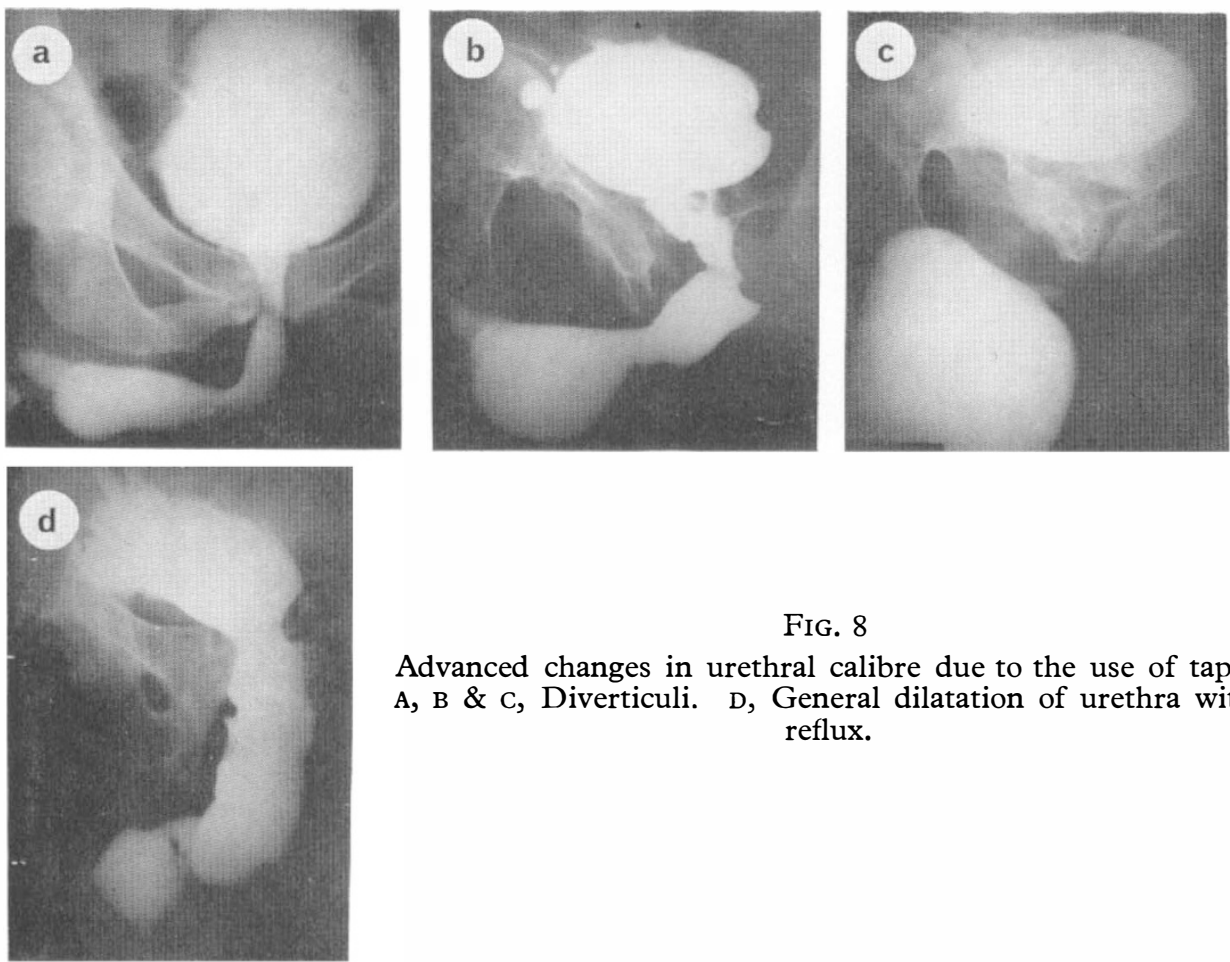

FIG. 8

Advanced changes in urethral calibre due to the use of tape. A, B \& C, Diverticuli. D, General dilatation of urethra with reflux.

lines and eliminate the hard roller ring. Dover, Cheesebrough Ponds, and Intermed have already complied with the idea (Fig. 9).

For years it has been customary and an accepted practice to wrap some kind of tape around the penis to secure the condom in place, even if the condom has been applied on the penis with surgical cement or other kind of adhesive substance. However, the question which has to be answered is this, Is it the cement or the adhesive substance which keeps the condom in place, or is it the application of tape? In our experience, and according to many of our patients, if cement and/or adhesive substances are applied properly, there won't be any need for the tape to keep the condom in place. Exceptions to this rule may be the patients in whom the penis is too small to accommodate the condom. However, the majority of this group of patients end up either in having penile implant to enable them to keep the condom on, or in having indwelling urethral or suprapubic catheter. Several of our chronic SCI patients have never used any tape to keep their condoms in place.

The less irritant and more reliable adhesives in our hands have been Tincture of Benzoin for temporary application of condom and Surgical Appliance Adhesive (Davol) for longer application. The latter adhesive substance is inflammable and its container should be kept at room temperature and away from any sparks or fire.

Our past experience with the use of urihesive tapes, applied under the condoms, to keep them in place, was not as satisfactory as described by deLeval and Louis (1978-79). Also, we do not feel that they eliminate the chances of penile and particularly the urethral compression. 


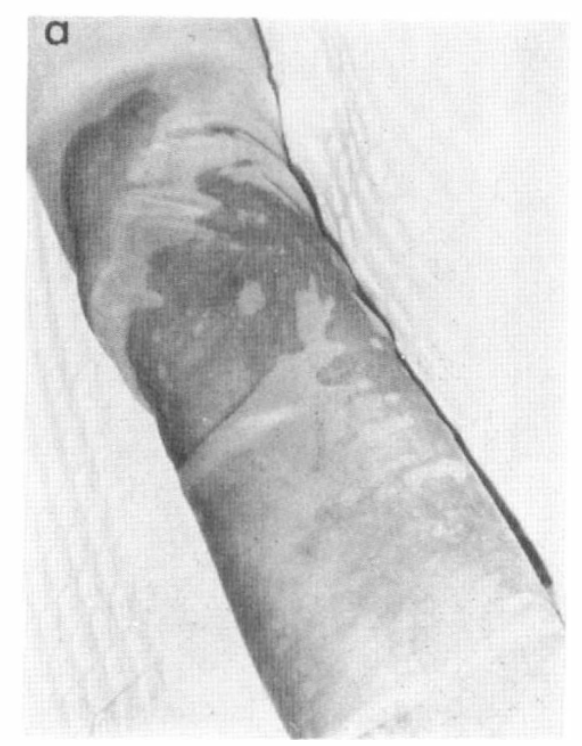

FIG. 9

The use of condom without hard roller ring or tape.

\section{Conclusion}

I. We estimate that more than 15 per cent of our SCI patients with external condom drainage develop some kind of penile or urethral complication, some of them very serious. This percentage has been reported to be about 30 per cent in patients wearing rubber urinals with penile sheath.

2. As preventive measures, the causes of urethral and penile compression may be eliminated by choosing the proper size condom, eliminating the roller rings of the condoms, and abstaining from the use of adhesive tapes on the penis.

\section{Discussion}

In order of frequency, the irritation and allergic reactions of skin, the limited pressure defects caused by the condom rings, oedema of prepuce, changes in urethral calibre and damages to the corpora are experienced in decreasing order. However, in terms of seriousness, the lesions of corpus spongiosum and corpora cavernosa are the front runners of all other complications (Figs 4, 5 and 6).

Aetiologically, there is no doubt that, in our patients, the compression exerted by the condom ring and/or the tape were the causes of observed penile lesions; however, it is not convincing to us that the changes in urethral calibre are exclusively due to increase in the intraurethral pressure resulting from urethral compression. Recently, the cystourethrograms of one of our newly injured patients showed minimal localised dilation of urethra, proximal to peno-scrotal junction, whereas he still was on intermittent catheterisation, his condom drainage was used only as a precautionary measure and he did not have urethral trauma or periurethral abscess. This finding suggests that more studies and follow-up are needed to rule out the possibility of infection and/or neurogenic dysfunction affecting the urethra, at least as a predisposing factor in causing urethral dilation. 
Acknowledgement; My sincere thanks and appreciation to my associates, Dr Feraidoun Khonsari and Dr Carl Nelson who have cared for some of the patients whose complications are reported. Also, I would like to express my gratitude to Mr Robert Walker, Miss Helen Vallerand, R.N., Ms Kay Kamrath and Ms Betty Shrout who were a great help in preparation of the photos and manuscript.

\section{SUMMARY}

As a result of recent advancements in urodynamic evaluation of male patients with spinal cord injury and improvement in medico-surgical treatment of bladder and sphincter, a high percentage of SCI patients are catheter free and on external condom drainage. However, the improper application of a condom in more than I5 per cent of these patients has caused a variety of complications, some of them very serious. Therefore, the common complications of condom application are described and illustrated. Also, the treatment of those complications are discussed and in particular the preventive measures are presented, and the importance of them stressed.

\section{RÉSUMÉ}

A cause de progrès récemment dans acquis les études urodynamiques chez les malades masculins avec la moelle épinière traumatisée et de perfectionnement médicochirugicale du traitement de la vessie et du sphincter, un grand pourcentage de ces malades ne portent pas de sonde et utilisent le condom (étui pénien). Pourtant l'usage défectueux du condom s'en résulte en complications diverses chez plus que $15 \%$ des malades; quelques unes sont très graves. C'est pourquoi dans ce travail on a décrit et démontré les complications. Le traitement de ces complications est discute, en particulier les moyens préventifs et l'importance de chaque moyen.

\section{ZUSAMMENFASSUNG}

Durch die neuen Fortschritte in urodynamischen Studien der männlichen Patienten mit Rücenmarksverletzungen und durch die verbesserte medicochirurgische Behandlung der Blase und des Sphinkters konnte ein großer Prozent katheterfreier Patienten die Kondom-Entleerung benutzen. Trotzdem die unrichtige Benutzung des Kondoms gab Komplikationen, manche sind schwere, in $15 \%$ der Patienten. Darum die gewöhnliche Komplikationen sind in dem Text erklärt und beschrieben. Die Behandlungsmethoden der Komplikationen sind besprochen, besonders die Prophylaxie und die Notwendigkeit jeder Mittel.

\section{REFERENCES}

De Leval, J. \& Louis, J. C. (1978-79). Urihesive, a new aid in the management of urinary incontinence in male paraplegic patients. Paraplegia, 16, 229-302.

LAwson, S. Q. \& Cook, J. B. (1978-79). An ergonomic appraisal of the use and functional efficiency of condom urinals in the male patient with spinal cord paralysis. Paraplegia, I6, 317-42I.

Naninga, John B. \& Rosen, Joel (1975). Problems associated with the use of external urinary collector in male paraplegic. Paraplegia, 13, 56-58. 